\title{
Sweet cherry phenology in the context of climate change: A systems biology approach
}

\author{
Bénédicte Wenden ${ }^{1}$, Mahendra Mariadassou ${ }^{2}$ \\ 1INRA, Univ. Bordeaux, UMR 1332 Biologie du Fruit et Pathologie, F-33140 Villenave d'Ornon, France \\ 2INRA, UR1404 Unité MaIAGE, F-78350 Jouy-en-Josas, France
}

\begin{abstract}
In temperate fruit trees, most key phenological stages are highly dependent on environmental conditions. In particular, correct timing for dormancy and flowering is essential to ensure good fruit production and quality. Consequently, a swiftly-changing environment will put temperate fruit crops at risk in the coming decades. Global changes in environmental conditions include warmer winters and higher risks of frosts in the early spring, which may lead to a wide range of problems in relation to flower and fruit set, sunscald, cross-pollination or novel host-pest interactions. In addition, hotter summers might affect fruit development and dormancy onset. Considering the time necessary to breed new cultivars better adapted to future climatic conditions, one of the strategies is to develop predictive tool as a support for simulating the behaviour of ideotypes in the context of warmer climatic scenarios. Here, we present a collection of sweet cherry flowering data from European sites. Statistical analyses conducted on 'Burlat' flowering dates collected in Bordeaux reveal the key periods for chill and heat accumulation during dormancy. Additionally, we propose a way of combining different data and approaches, and integrate them into a predictive model as an assisting tool for sweet cherry breeding strategies.
\end{abstract}

Keywords: Prunus avium L., Flowering time, Partial Least Square Regression (PLSR), Modelling

\section{INTRODUCTION}

Global climate change has been extensively studied and much evidence now points to a strong impact on biological systems across the globe (Jochneret al., 2016; Parmesan and Yohe, 2003; Root et al., 2003), including changes in the timing of phenophases in fruit trees (MillerRushing et al., 2007). Current estimates of advancing phenology for forest and fruit trees, including earlier leaf unfolding and flowering, range between 1.9 and 7.7 days per ${ }^{\circ} \mathrm{C}$ (Jochner et al., 2016; Menzel et al., 2006; Wolkovich et al., 2012). However, the effect of climate change on phenology is very complex and in some locations, spring phases have been observed to occur later (Atkinsonet al., 2013; Elloumi et al., 2013), which might reveal the impact of warmer autumn and winter temperatures on lack of chill accumulation during dormancy.

Such alterations might threaten temperate fruit production and may thus affect global economy. As a consequence, it is essential to foresee the changes needed in agriculture and to breed new cultivars better adapted to future climatic conditions. As fruit trees are grown for many years and their breeding processes can take several decades, one of the options is to develop predictive tools that will help simulate the behaviour of ideotypes in the context of warmer climatic scenarios. Here, we propose a way of combining different data and approaches, and integrate them into a predictive model as an assisting tool for sweet cherry breeding strategies.

In particular, a better understanding of temperature response and sensitivity of fruit trees phenology is essential to foresee the changes to come and to have the ability to overcome the effects of climate change on fruit tree productivity. The aim of this study was to provide preliminary information for the identification of trends in sweet cherry flowering response to temperature response. We then discuss options and for the development of predictive tools for sweet cherry phenology.

\section{MATERIALS AND METHODS}


Following the collection of a wide range of sweet cherry flowering data across Europe, we used partial least squares (PLS) regression to detect distinct temperature phases as demonstrated on walnuts in California (Luedeling and Gassner, 2012), cherry trees in Germany (Luedeling, Kunz, \& Blanke, 2013) and cherry and chestnuts in China (Guo at al., 2013). In this study, we tested the PLS approach to analyse the temperature sensitivity of 'Burlat' as reference and the most widelygrown cultivar for sweet cherry, in our experimental orchard (Bordeaux, France) and analysed its flowering response to cold and warm temperatures.

\section{Flowering data collection}

Sweet cherry flowering data for 'Burlat' (Table 1) from 22 different locations were collected using two networks: a French national network of experimentation (coordinated by the Centre technique interprofessionnel des fruits et legumes - CTIFL) for the French data and a network of collaborators derived from the European COST Action (FA1104).

Table 1. Countries of data origin and years of cherry flowering observation of the cv. 'Burlat' across Europe

\begin{tabular}{lccc}
\hline Country & Latitude & $\begin{array}{c}\text { Number of } \\
\text { experimental } \\
\text { sites }\end{array}$ & Years of observation \\
\hline Belgium & 50.55 & 1 & $1989-2014$ \\
Bulgaria & 42.11 & 1 & $2006-2011$ \\
France & $42.76-48.47$ & 11 & $1981-2015$ \\
Germany & $50.62-53.51$ & 2 & $1978-2015$ \\
Italy & 44.22 & 1 & $1991-2015$ \\
Norway & 60.32 & 1 & $1995-2007$ \\
Serbia & 43.88 & 1 & $1992-2014$ \\
Spain & $38.04-41.70$ & 4 & $1994-2015$ \\
Switzerland & 43.22 & 1 & $1979-2007$ \\
\hline
\end{tabular}

\section{Partial Least Square Regression}

For PLSR analyses, we used a subset of data from Bordeaux (France). In total 180 flowering dates were recorded for 'Burlat' at the experimental orchard of INRA Bordeaux research centre located in Toulenne near Bordeaux, France $\left(44.58^{\circ} \mathrm{N},-0.28^{\circ} \mathrm{E}\right)$ for 32 years of observation from 1981 to 2012.

Short gaps in daily temperature data were closed by linear interpolation, as described in Luedeling et al. (2013). As proposed in Luedeling and Gassner (2012), an 11-day running mean of daily temperatures was constructed, which smoothes the temperature curve and eases the interpretation of PLS regression (PLSR) outputs.

In addition, the $\mathrm{R}$ package ChillR (Luedeling, 2013) which includes all procedures described in the different PLSR studies on fruit trees was used (Guo et al., 2013; Luedeling and Gassner, 2012; Luedeling et al., 2013). These functions were used to analyze the response of sweet cherry cv. 'Burlat' flowering dates to variation in mean daily temperatures during the 365 days of the year, from July to June.

The major outputs of the PLS analysis are the variable importance in the projection (VIP) and standardized model coefficients. Periods with VIP scores higher than the threshold set to 0.8 as previously described (Luedeling and Gassner, 2012), and high absolute values of model coefficients represent the relevant phases, when temperatures have a significant effect on flowering dates in 'Burlat'. Positive coefficients in the chilling phase indicate that higher temperatures during the given period delay flowering, or that temperatures lower than the 
average hasten flowering, whereas negative coefficients reveal that warmer temperatures lead to earlier flowering dates.

\section{RESULTS AND DISCUSSION}

\section{Flowering data collection}

Flowering data were checked for consistency and long time series for the sweet cherry cv. 'Burlat' confirmed a relation between flowering dates and latitudes, with flowering periods being significantly later in Northern growing sites (Figure 1). Although the dataset is not homogeneous regarding the record length, they represent a valuable asset for phenological studies, phenology models having been successfully tested and optimized using data sourced from different sites (Andreini et al., 2014; Darbyshire et al., 2016).

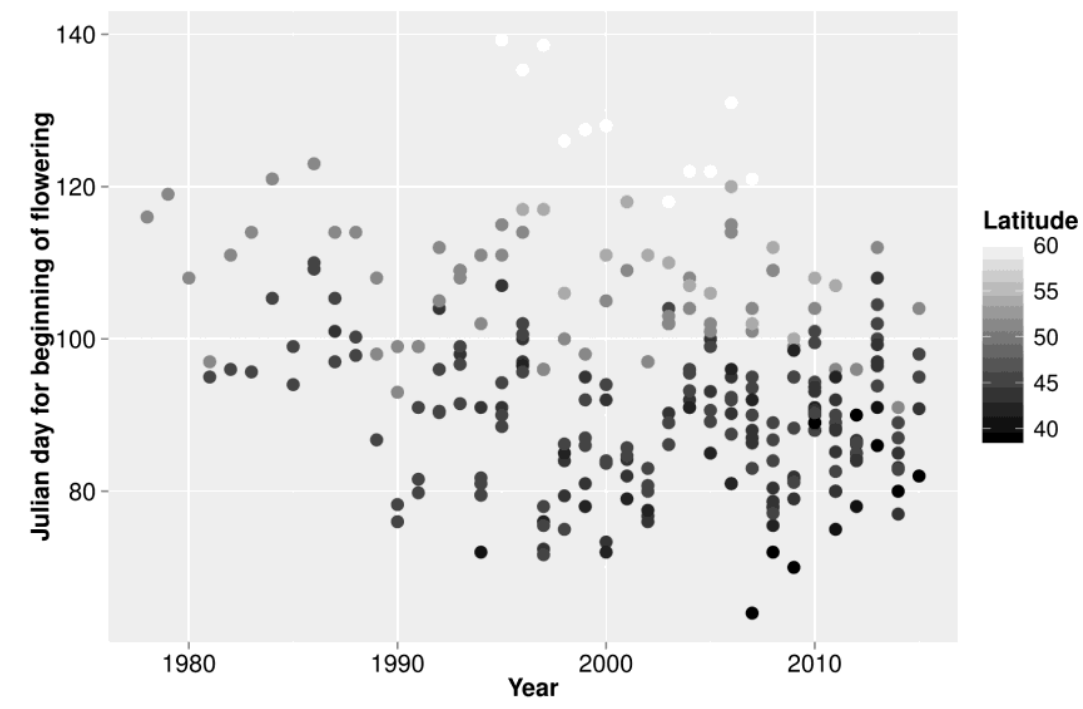

Figure 1. Average date of beginning of flowering of the sweet cherry cv 'Burlat' collected from 23 experimental sites across Europe.

\section{Flowering dates response to temperatures: example of Bordeaux (France)}

In order to test the possibility to extract information on the flowering sensitivity to temperatures, we fitted a PLSR model for 'Burlat' flowering dates against average daily temperatures. PLSR coefficients give information on the strength and the cold/warm effect of temperatures on flowering time. However, only the periods characterized by a VIP threshold value greater than 0.8 , are considered to have a significant effect of the temperatures on flowering time. Although the coefficients varied greatly over the 365 days, two main distinct groups of significant coefficients were identified (Figure 2).

The timing of flowering is directly dependent on a proper dormancy release and bud growth, which are controlled by environmental factors, mainly temperature in sweet cherry. Winter bud dormancy can be divided into two main stages: endodormancy followed by ecodormancy (Lang et al., 1987). During endodormancy, even under optimal climatic conditions, the plant ceases to grow until sufficient accumulation of cold temperatures, namely chilling requirements, to trigger dormancy release. Subsequently, ecodormancy starts when buds are able to grow but low temperatures inhibit bud break. Flowering occurs when temperatures increase and heat requirements for bud growth are satisfied. Consequently, for endodormancy, we expected to clearly identify chilling periods defined by positive coefficients with highly significant VIP in the PLSR results. However, there was no relevant pattern in autumn and winter temperatures except for one distinct peak with VIP values greater than 0.8 at the end of September 
(Figure 2). This lack of significant cold effect validates the absence of limitation in terms of cold temperature during the major part of winter, meaning that the low winter temperatures in Bordeaux appear to be sufficient to fulfill 'Burlat' chill requirements every year. The high statistical coefficients in September may indicate significant effects of particularly cold temperatures before dormancy onset with the physiological mechanisms remaining obscure at the moment.

PLSR results show a significant peak with positive statistical coefficients in July (Figure 2). Rather than a positive cold effect on flowering time, it is likely that during this period, warm if not hot temperatures negatively affect dormancy onset. Jonkers (1979) demonstrated a tendency for dormancy to deepen when the temperatures, at which the apple and pear buds had been formed

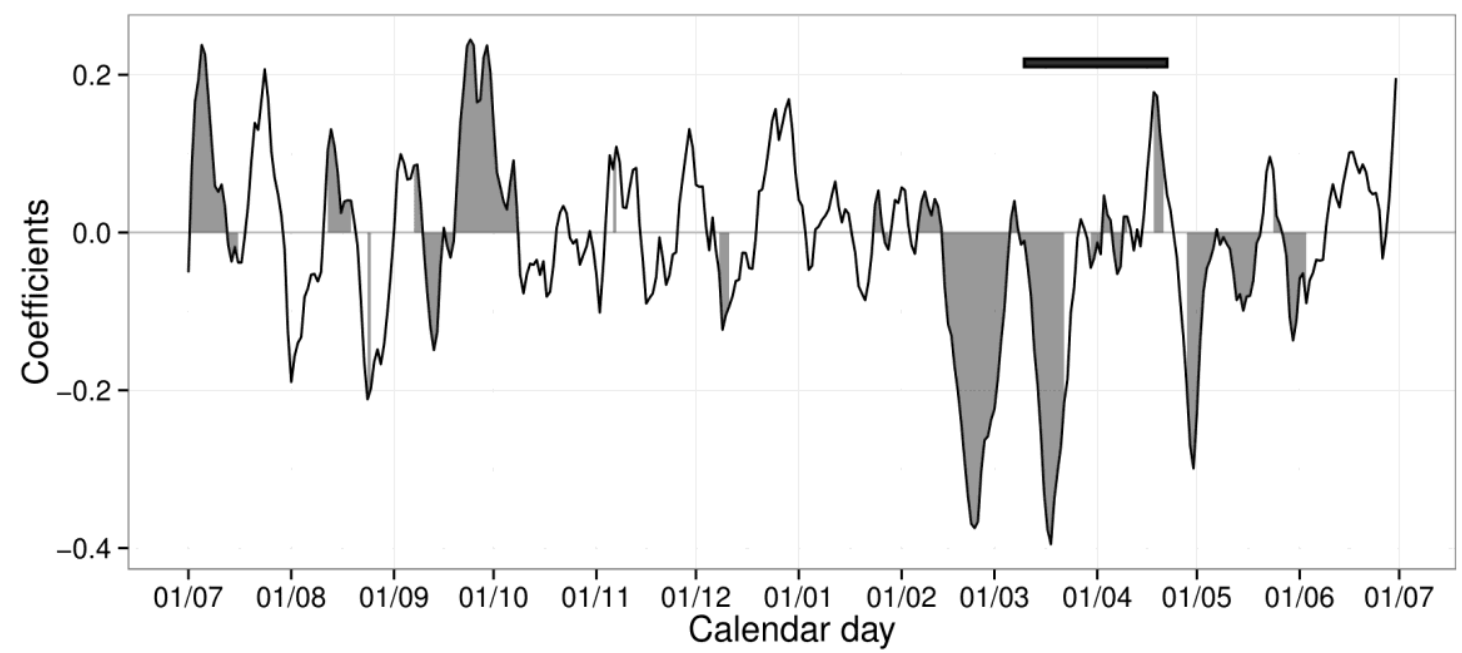

Figure 2. Results for the model coefficients of Partial Least Squares (PLS) regression for beginning of flowering dates in sweet cherry cv. 'Burlat' in Bordeaux (France), in correlation with mean daily temperature, averaged over 11 days, from July $1^{\text {st }}$ (Year N-1) to June 30th (Year N). Grey areas indicate that the Variable Importance on Projection (VIP) is greater than 0.8 , corresponding to the threshold chosen for significant effect of the temperatures on flowering time. Positive coefficients indicate that warm temperatures during the given period delay flowering, or that cold temperatures hasten flowering, whereas negative coefficients reveal that warmer temperatures lead to earlier flowering dates. The top black horizontal line indicates the flowering dates over the observation years (1981-2012).

were too high.

Around February and March, negative coefficients with high absolute values and VIP values exceeding 0.8 corresponded to a critical phase, when warm temperatures were needed to hasten ('force') flowering in sweet cherry cv. 'Burlat'. This is in agreement with the heat requirement period, related to the ecodormancy. Highly significant results confirm that climatic conditions mostly affect flowering time through temperatures at the end of winter. These results are consistent with the forcing phase previously identified in Bonn (Germany) for the sweet cherry cv. 'Schneiders spate Knorpelkirsche' (Luedeling et al., 2013).

\section{Towards predictive models and tools for sweet cherry flowering time}


In the current context of climate change, breeding strategies for fruit trees aim at obtaining cultivars well adapted to future climatic conditions, while sustaining good production. Precise phenological modelling represents a valuable tool as a support to select the best genotypes but also to assess the risks for production areas. Predictive models for chill availability project an increase in this delaying effect of mild winters as temperature increase becomes more pronounced (Luedeling, 2012; Vitasse et al., 2011), especially in warmer locations (Guo et al., 2015).Consequently, phenology models can predict the regions that will become unfavourable in terms of optimal conditions for growth and production (Ford et al., 2016) or highlight the future safe areas (Darbyshire et al., 2013). This approach represents a valuable decision-making assistance for cherry production, notably for the choice of cultivars adapted to upcoming climatic conditions in threatened areas (Measham et al., 2014).

At another biological scale, predictive tools based on genetic and physiological knowledge of the response to environmental conditions may allow accurate simulation of the behaviour of given genotypes under particular climatic scenarios. These models will help designing ideotypes, i.e. "model plants", and in particular adjusting the optimal allele combinations, under future climatic conditions, such as warmer winters or wet springs, as it has been reviewed for cereals (Rötter et al., 2015). Overall, predictive modelling approaches represent powerful tools to assist the breeding strategies in overcoming the complexity of all mechanisms involved in the temperature responses. Phenology models are very valuable for assessing the impact of temperature but at the moment they are limited by their lack of transferability between sites and cultivars (Linkosalo et al., 2008; Luedeling and Brown, 2011). Therefore, the future approaches for predictive models should be based on more precise phenological observations such as dormancy release dates, more environmental parameters including photoperiod (Chmielewski and Götz, 2016) and molecular mechanisms (Satake et al., 2013). We propose a process to build such predictive models for sweet cherry phenology based on a wide range of data and hypotheses (Figure 3).
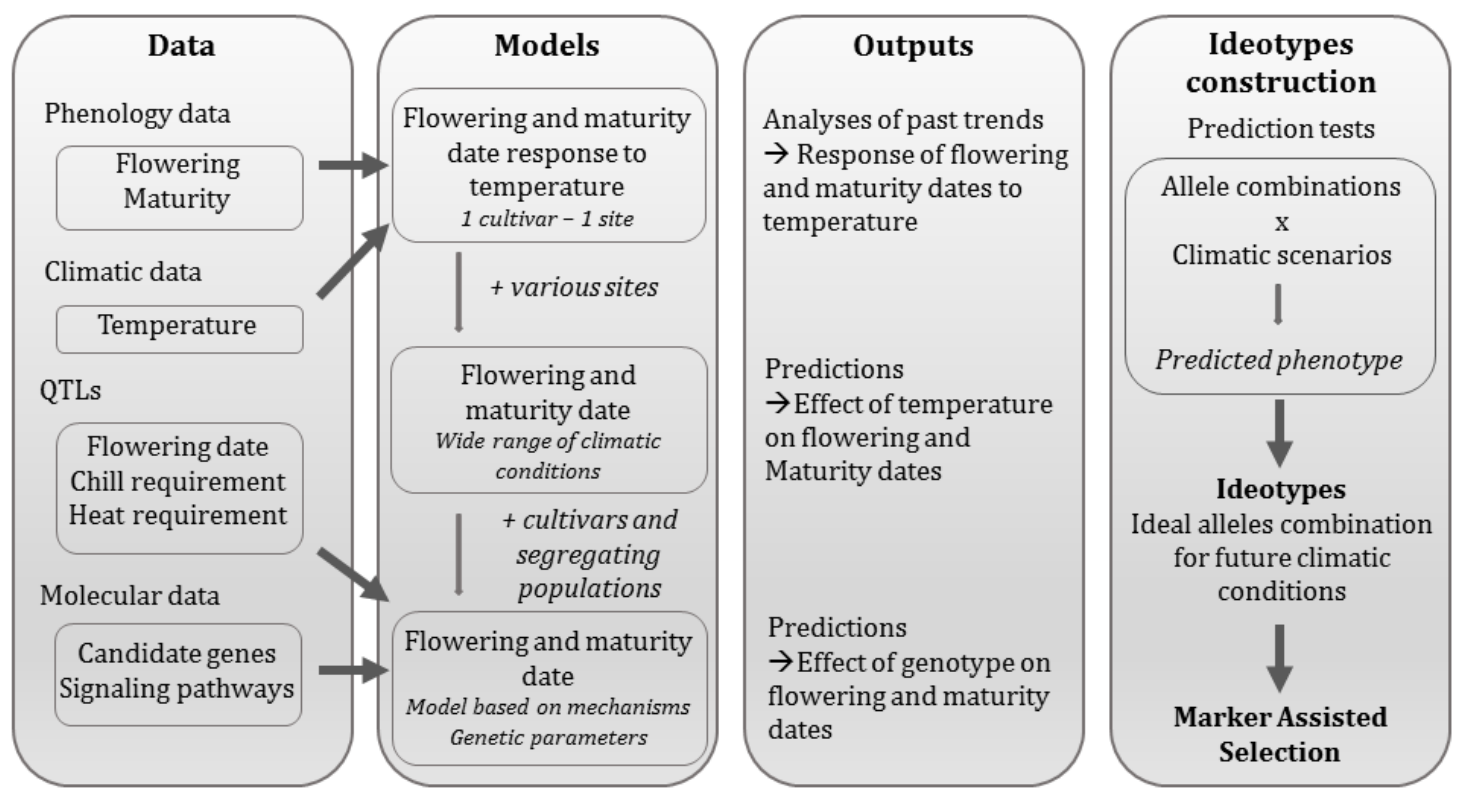

Figure 3. Integrating phenology, genetic, molecular and climatic data into a predictive tool as a support for ideotype design and marker assisted selection. 
Based on exploratory analyses of phenology data, including the PLS regression, current phenological models can be improved with the addition of the key periods during which the temperatures have a significant effect on flowering and maturity. Subsequently, the analyses of flowering data for several sites, characterized by highly contrasted climates, should lead to predictive models that can be used for a wide range of climatic conditions (Figure 3).However, in order to apply predictive models to various cultivars, genetic data are indispensable in order to avoid re-parameterizing for each new genotype. Several approaches were already proposed to simulate traits based on genetic and molecular determinisms including gene-based (Messina et al., 2006), QTL-based (Yin et al., 2005) and multiscale models (Chew et al., 2014). In sweet cherry, a multiyear analysis of flowering time and chilling and heat requirements led to the identification of QTLs (Castède et al., 2014) and genomic and molecular studies conducted in woody perennials have identified candidate genes and signalling pathway s involved in the control of phenology (Ríos et al., 2014). These data, combined with knowledge acquired through on-going experiments, will support new hypotheses for the development of predictive models based on genetic and/or molecular parameters. Such integrative models will support the evaluation of cultivar suitability and the ideotype design under climate change, but will also provide key information for marker assisted selection (Figure 3).

\section{AKNOWLEDGEMENTS}

The authors are grateful to the EU COST Cherry FA1104 action for enabling and financially supporting the Working Group 2 workshop on Cherry Phenology in Ullensvang in April 2014 and for financing the publication of these results in Acta.

\section{Literature cited}

Andreini, L., García de Cortázar-Atauri, I., Chuine, I., Viti, R., Bartolini, S., Ruiz, D., Campoy, J.A., Legave, J.M., Audergon, J.M. and Bertuzzi, P. (2014). Understanding dormancy release in apricot flower buds (Prunus armeniaca L.) using several process-based phenological models. Agric. For. Meteorol. 184, 210-219.

Atkinson, C. J., Brennan, R. M., and Jones, H. G. (2013). Declining chilling and its impact on temperate perennial crops. Environmental and Experimental Botany.91, 48-62.

Castède, S., Campoy, J. A., Quero-García, J., Le Dantec, L., Lafargue, M., Barreneche, T., ... Dirlewanger, E. (2014). Genetic determinism of phenological traits highly affected by climate change in Prunus avium: flowering date dissected into chilling and heat requirements. The New Phytologist, 202(2), 703-15.

Chew, Y. H., Wenden, B., Flis, a., Mengin, V., Taylor, J., Davey, C. L., ... Millar, a. J. (2014). Multiscale digital Arabidopsis predicts individual organ and whole-organism growth. Proceedings of the National Academy of Sciences, 1-10.

Chmielewski, F.-M., and Götz, K.-P. (2016). Performance of models for the beginning of sweet cherry blossom under current and changed climate conditions. Agricultural and Forest Meteorology, 218-219, 85-91.

Darbyshire, R., Webb, L., Goodwin, I., and Barlow, E. W. R. (2013). Impact of future warming on winter chilling in Australia. International Journal of Biometeorology, 57(3), 355-366.

Darbyshire, R., Pope, K. and Goodwin, I. (2016). An evaluation of the chill overlap model to predict flowering time in apple tree. Sci. Hortic. 198, 142-149.

Elloumi, O., Ghrab, M., Kessentini, H., and Ben Mimoun, M. (2013). Chilling accumulation effects on performance of pistachio trees cv. Mateur in dry and warm area climate. Scientia Horticulturae, 159, 80-87.

Ford, K. R., Harrington, C. A., Bansal, S., Gould, P. J., and St Clair, J. B. (2016). Will changes in phenology track climate change? A study of growth initiation timing in coast Douglas-fir. Global Change Biology.doi: 10.1111/gcb.13328

Guo, L., Dai, J., Ranjitkar, S., Xu, J., and Luedeling, E. (2013). Response of chestnut phenology in China to climate variation and change. Agricultural and Forest Meteorology, 180, 164-172.

Guo, L., Dai, J., Wang, M., Xu, J., and Luedeling, E. (2015). Responses of spring phenology in temperate zone trees to 
climate warming: A case study of apricot flowering in China. Agricultural and Forest Meteorology, 201, 1-7.

Jochner, S., Sparks, T. H., Laube, J., and Menzel, A. (2016). Can we detect a nonlinear response to temperature in European plant phenology? International Journal of Biometeorology, 60, 1551-1561.

Jonkers, H. (1979). Bud dormancy of apple and pear in relation to the temperature during the growth period. Scientia Horticulturae, 10(2), 149-154.

Lang, G., Early, J., Martin, G., and Darnell, R. (1987). Endo-, para-, and ecodormancy: physiological terminology and classification for dormancy research. Hort Science, 22(3), 371-377.

Linkosalo, T., Lappalainen, H., and Hari, P. (2008). A comparison of phenological models of leaf bud burst and flowering of boreal trees using independent observations. Tree Physiology, 28(12), 1873-82.

Luedeling, E. (2012). Climate change impacts on winter chill for temperate fruit and nut production: A review. Scientia Horticulturae, 144, 218-229.

Luedeling, E., and Brown, P. H. (2011). A global analysis of the comparability of winter chill models for fruit and nut trees. International Journal of Biometeorology, 55(3), 411-21.

Luedeling, E., and Gassner, A. (2012). Partial Least Squares Regression for analyzing walnut phenology in California. Agricultural and Forest Meteorology, 158-159, 43-52.

Luedeling, E., Guo, L., Dai, J., Leslie, C., and Blanke, M. M. (2013). Differential responses of trees to temperature variation during the chilling and forcing phases. Agricultural and Forest Meteorology, 181, 33-42.

Luedeling, E., Kunz, A., and Blanke, M. M. (2013). Identification of chilling and heat requirements of cherry trees-a statistical approach. International Journal of Biometeorology, 57(5), 679-89.

Measham, P. F., Quentin, A. G., and MacNair, N. (2014). Climate, winter chill, and decision-making in sweet cherry production. HortScience, 49(3), 254-259.

Menzel, A., Sparks, T. H., Estrella, N., Koch, E., Aasa, A., Ahas, R., ... Zust, A. (2006). European phenological response to climate change matches the warming pattern. Global Change Biology, 12(10), 1969-1976.

Messina, C., Jones, J. W., Boote, K. J., and Vallejos, C. E. (2006). A gene-based model to simulate soybean development and yield responses to environment. Crop Sci., 46, 456-466.

Miller-Rushing, A. J., Katsuki, T., Primack, R. B., Ishii, Y., Lee, S. D., and Higuchi, H. (2007). Impact of global warming on a group of related species and their hybrids: cherry tree (Rosaceae) flowering at Mt. Takao, Japan. American Journal of Botany, 94(9), 1470-8.

Parmesan, C., and Yohe, G. (2003). A globally coherent fingerprint of climate change impacts across natural systems. Nature, 421(6918), 37-42.

Ríos, G., Leida, C., Conejero, A., and Badenes, M. L. (2014). Epigenetic regulation of bud dormancy events in perennial plants. Frontiers in Plant Science, 5, 247.

Root, T., Price, J., Hall, K., Schneider, S., Rosenzweig, C., and Pounds, A. (2003). Fingerprints of global warming on wild animals and plants. Nature, 421(6918), 57-60.

Rötter, R. P., Tao, F., Höhn, J. G., and Palosuo, T. (2015). Use of crop simulation modelling to aid ideotype design of future cereal cultivars. Journal of Experimental Botany, 66(12), 3463-3476.

Sánchez-Pérez, R., Del Cueto, J., Dicenta, F., and Martínez-Gómez, P. (2014). Recent advancements to study flowering time in almond and other Prunus species. Frontiers in Plant Science, 5(July), 334.

Satake, A., Kawagoe, T., Saburi, Y., Chiba, Y., Sakurai, G., and Kudoh, H. (2013). Forecasting flowering phenology under climate warming by modelling the regulatory dynamics of flowering-time genes. Nat Commun, 4, 2303.

Vitasse, Y., François, C., Delpierre, N., Dufrêne, E., Kremer, A., Chuine, I., and Delzon, S. (2011). Assessing the effects of climate change on the phenology of European temperate trees. Agricultural and Forest Meteorology, 151(7), 969-980.

Wolkovich, E. M., Cook, B. I., Allen, J. M., Crimmins, T. M., Betancourt, J. L., Travers, S. E., ... Cleland, E. E. (2012). Warming experiments underpredict plant phenological responses to climate change. Nature, 485(7399), 494-497.

Yin, X., Struik, P. C., van Eeuwijk, F. A., Stam, P., and Tang, J. (2005). QTL analysis and QTL-based prediction of flowering phenology in recombinant inbred lines of barley. J Exp Bot, 56(413), 967-976. 